\title{
The Use of Real Life Contexts in the CTA: Some Unintended Consequences
}

\author{
Sarah Bansilal \\ University of KwaZulu-Natal \\ bansilal@ukzn.ac.za
}

\begin{abstract}
The Common Tasks for Assessment (CTA) was a new assessment programme that was introduced in 2002 in South Africa for all Grade 9 learners. The purpose of this paper is to articulate some concerns around the use of contextualised assessment activities in the CTA. The study reported here was carried out in 2003. Data for the study was generated from lesson observations and interviews with the participant teachers and groups of learners. It is argued that although the intentions behind the design of the CTA are well meaning and noble, there are in fact some learners who may be unintentionally disadvantaged by the design of the CTA which uses an extended context as a source for all the assessment tasks. In this paper two unintended consequences of using 'real life' contexts are identified and the implications of these are discussed, by linking the observations to research carried out in the UK and the USA.
\end{abstract}

The purpose of this paper is to explore some unintended consequences arising from the use of real life contexts in the design of the externally mandated national assessment programme in the form of the Common Tasks for Assessment (CTA). I present two vignettes of two Grade 9 mathematics classrooms drawn from a study of the classroom practices of two mathematics teachers who were participants in a study in 2003 which explored the mathematics teachers' professional knowledge by looking at how and why the teachers mediated the CTA in the ways that they did (Bansilal, 2006). The abovementioned study was carried out on four participant teachers, and their Grade 9 learners drawn from three different schools.

In this paper, I focus on some unintended consequences arising from the use of these "real life" contexts in the assessment tasks, which have implications for the validity of these tasks as assessment tools. Firstly, the issue of contexts which are out of certain learners' experiences is highlighted. In the first vignette, we are introduced to a teacher, who in compensating for her learners lack of knowledge of pizzas, simplifies the actual assessment task. Her actions seem to be within her prescribed role of helping her learners to succeed (Department of Education (DOE), 2002), but her intervention results in a simpler task. In the second vignette we are introduced to a learner, Sipho, who displays a tendency to respond to the task based on his everyday experiences. The discussion is then focused on how learners could be disadvantaged by their propensity to base their responses on their everyday experiences instead of the mathematical considerations that are required by the task designers. These observations are linked to some concerns raised by Cooper and colleagues (Cooper \& Dunne, 1998; Cooper \& Harries, 2003) about certain learners being disadvantaged by the use of such contextualised tasks in national assessment programmes in the UK as well as the work of Boaler (2003) with respect to the Stanford Achievement Test (SAT)-9 assessment programme in the USA.

The organisation of the paper is as follows: In the background section, I first present some background surrounding the CTA programme before discussing some research around the use of "real life" contexts in assessment tasks. I then briefly discuss the design of the study, and thereafter two vignettes are presented. Each vignette is followed by a reflective commentary which identifies and clarifies the main points raised. Thereafter I discuss the implications of the findings by relating the identified points to relevant research and I end off the paper by identifying areas for further research. 


\section{Background}

As part of the broader curriculum reform process occurring in South Africa, a new assessment programme at the Grade 9 exit level of the GET phase was introduced in 2002. The Common Tasks for Assessment (CTA) was completely different in approach, form and substance from the Senior Certificate examination which is written at the end of the 12 years of schooling.

The document: Draft Framework for the Development of the CTA's (DOE, 2002) was circulated in 2002 and it is this document that I use to trace some guiding principles and the rationale behind the design of the CTA. Initially there were two parts to the CTA, Section A which focused on the assessment of performance-based competencies and Section B which focused on "competencies that could be assessed with paper and pencil form of assessment" (DOE, 2002, p. 6). However the Section B of the CTA did not appear in the years 2004 to 2006, but reappeared in 2007. This paper is based on the Section A of the CTA programme in 2003.

The CTA was intended to be "used as an external summative assessment instrument" (DOE, 2002, p. 4). The Framework document articulates strong concerns that learners should not be disadvantaged by their abilities, language skills and learning styles. For example some recommendations are that the tasks should "accommodate the diversity of learning styles and abilities" (p. 12), "consider the diverse learning styles and learning needs ... [and] determine how adaptations could be built in to address barriers to learning" (p. 14) and "should avoid all biases, e.g., language, urban and rural contexts, gender, disability, etc." (p. 12). These excerpts convey a strong recommendation that learners with different learning styles must be accommodated and that the tasks should not have language or context biases which may lead to certain learners being disadvantaged by their backgrounds.

An interesting and unusual suggestion (for summative assessment tasks) was that the teacher could play an active role during the assessment programme in order to help learners overcome their barriers. One of the stipulations was that the CTA tasks should be structured "so that teachers can help learners succeed" (DOE, 2002, p. 12). The document contains references to a teacher's manual which should be used to guide the teacher. The framework document states that the manual should "specify clearly what the teacher is expected to do in each activity" (p. 8). However, none of the participant teachers had seen such a manual. It is possible that the manual had been reduced to the marking memorandum, which all the teachers had received. In the absence of detailed guidance on the interventions that were permissible, teachers exercised their own judgments and intervened in different ways, ranging from not providing any hints at all, to working out certain tasks in the class (Bansilal, 2006). It will be seen from the discussion that this combination of the use of "real life" contexts with the stipulation that teachers were allowed to intervene, produced a particular set of threats to valid assessment.

The Department of Education was explicit that the CTA should be designed as performance based assessment tasks; the Framework document states that the "...[CTA] will target outcomes not best assessed in a pencil and paper exercise, ... should be based on performance-based assessment" (p. 9). The document explains performance based assessment:

Performance-based assessment permits learners to show what they can do in a real life situation, i.e. this is a type of assessment that emphasises the learners' ability to use or transfer their knowledge, understanding and skills into action. ... Performance-based assessment provides a systemic way of evaluating those reasoning skills and outcomes ... that cannot be assessed adequately by a paper and pencil test. (DOE, 2002, p. 9)

It is emphasised once again (on p. 12) that the tasks "should be grounded in real life contexts". The above excerpts demonstrate the DOE's intention to move the assessment away from pencil and paper tests and conveys the view that assessment tasks set within real life contexts are able to accommodate the diverse learning styles and learning needs of the South African learner population. However, I will argue that in fact certain learners are disadvantaged by their tendency to base their responses on their everyday experiences.

Looking at mathematics in "real life" or "real world" contexts is a common refrain heard by teachers, learners and parents throughout the world. Moschkovich (2002) explains that real world when used to describe curriculum assessments, or mathematical activity can refer to activities in which students might 
engage during the course of their present daily lives or to future activities in which students might engage as adults at work. This emphasis on "real life" contexts is a common trend in mathematics curricula globally. Cooper and Dunne (1998) note that in recent years, in the UK, there has been an increasing emphasis on understanding, investigation and the application of mathematics in realistic settings, as opposed to the emphasis in the 1960s of abstract algebraic approaches. Moschkovich (2002) states that curriculum and teaching standards, in the USA, for the mathematics classroom have made calls for engaging students in real world mathematics rather than mathematics in isolation.

A powerful use of contexts is in the mediation of the teaching of new mathematical concepts. The real world can be a source of analogies that can be used to make the mathematical ideas more relevant and more meaningful for learners. One well-known theory of learning is that proposed by the Realistic Mathematics Education school of thought which has its roots in Freudenthal's interpretation of mathematics as a human activity. Within this philosophy, learners are encouraged to learn mathematics by mathematising subject matter from real contexts and their own mathematical activity, rather than presenting mathematics to them as a ready-made system with general applicability (Gravemeijer, 1994). Real situations may include contextual problems or mathematically authentic contexts for learners where they experience the problem presented as relevant and real. Examples of such contexts can be found in Freudenthal, (1983), Linchevski and Williams (1996) and William(1997).

Boaler (1993) wrote:

The move away from the teaching of mathematics as a complete series of abstract calculations has also been supported by a number of different assertions regarding the enhancement of mathematical understanding. The abstractness of mathematics is synonymous for many with a cold, detached remote body of knowledge....[an image that] may be broken down by the use of contexts which are more subjective and personal also improving the ability of students to interpret events around them. (p. 2)

However, the simplistic assumption that the use of contexts provides meaning and improves the understanding of mathematical concepts is challenged by certain researchers. Arcavi (2002) cautions us that familiarity with a context does not necessarily make the understanding of the mathematics easier. He uses the example of $\mathrm{f}(x)=x$ to show that a mathematical idea may sometimes be easier to use and conceptualise in a de-contextualised environment than in a familiar context. Evans (1995) criticises the simplistic notion that giving real world contexts for mathematical concepts provides meaning for learners - a meaning that supposedly exists in some absolute sense and is illustrated by or modelled in that real world context.

In a similar vein, William (1997) notes that sometimes contexts are used which bear little or no relation to the mathematics being taught and which serve primarily to legitimate the subject matter being taught ("mathematics looking for somewhere to happen"). Boaler (1993) states that "misconceptions prevail such as the belief that mathematics in an "everyday' context is easier than its abstract equivalent" and notes that the degree to which the context of a task affects students' performance has been widely underestimated.

Boaler's (2003) assertion that teaching situations in which students are learning are very different from standardised assessments in which they are being tested, has direct reference to this paper. I am not taking issue with the use of realistic mathematics contexts to enhance understanding of various mathematical concepts - my focus is on the use of realistic contexts in the mathematics CTA programme. In particular, I am concerned about the ways in which certain learners could be disadvantaged by some unintended consequences brought about by, the design of the tasks and/or assumptions about learners experiences. Cooper has written extensively with various colleagues (Cooper, 1998; Cooper \& Dunne, 1998; Cooper, Dunne \& Rodgers, 1997; Cooper \& Harries, 2003) about the use of these real life contexts in National Assessment tasks in the UK. Cooper and his colleagues' studies alert us to the danger of certain learners' abilities being underestimated by national assessment tasks set within real life contexts. The use of these "realistic" test items may present the danger of learners relying on their everyday knowledge instead of their mathematics knowledge. When learners get confused about which knowledge to draw upon, it may not mean that they do not know the mathematics, but it may just mean that they did not realise what they were being asked for. Cooper and Dunne (1998) used Bernstein's theory to demonstrate how questions 
that were set in everyday contexts in national mathematics tests in the U.K disadvantaged working-class children. Cooper and Dunne (1998) drew upon data from primary schools to show why certain "realistic" mathematics test items were associated with the under-estimation of children's actually existing capacities in mathematics and that the extent of such under-estimation varied by social class.

\section{The study}

The data presented in this paper was drawn from a larger study designed to explore the professional knowledge of four Grade 9 mathematics teachers in the context of mediating the 2003 CTA (Bansilal, 2006). The methodology employed was a case study approach. Cohen, Manion and Morrison (2000) maintain that case studies provide a unique example of real people in real situations, enabling readers to understand the events more clearly than simply presenting them with abstract theories or principles. In order to understand the teachers' actions, the case study allowed me to focus on the particularity of each teacher's context. Data for the larger study was generated from classroom observations, semi-structured and informal interviews and my field notes. During the analysis stage of the research study mentioned above, certain compelling aspects related to learners' experiences of the real life contexts used in the CTA, came to the fore. It is my purpose, in this paper to raise some of these issues related to the learners' experiences of the CTA.

In this paper I use my field notes, journal entries, and lesson and interview transcripts to construct two vignettes - A party without pizzas and Sipho and the weather in Durban. The vignettes are constructed using Polkinghorne's (1995) narrative analysis technique where the data elements are configured into a story that unites and gives meaning to the data. Accompanying each vignette is a reflective commentary, on issues pertaining to the central research question: What are some unintended consequences of using real life contexts in the CTA? This question is then explored in further detail in the discussion section of the paper using Polkinghorne's (1995) analysis of narratives strategy applied to the two vignettes. The focus in this paper is not on the teachers' pedagogic styles or repertoires.

\section{Vignette 1: A party without pizzas}

The setting for this vignette is Vanitha who is teaching in an ex-HOD school in a Durban South township, where most of her learners are African.

In this lesson, Vanitha was involved in preparing her learners to respond to a task whose context was out of her learners' experience. The task is provided below.

\section{Task Three: Activity 2 (Pairs)}

At a restaurant at the Waterfront in Cape Town, tourists have a choice of different pizzas:

$\begin{array}{ll}\text { BASE } & \text { TOPPINGS } \\ \text { Thick } & \text { Pineapple } \\ \text { Regular } & \text { Salami } \\ \text { Tuna } & \end{array}$

Mushroom

If a tourist buys a pizza with three toppings, how many combinations are possible?

(Use any systematic counting method that you have learnt.)

I was surprised when Vanitha started her lesson off by inviting her learners to a Diwali party instead of discussing the CTA task. However I soon realised that she was using the context of party with drinks and snacks to introduce the meaning of combinations. The following excerpt from her lesson illustrates her strategy of using a similar task that was set within a different context (of providing refreshments) to mediate the CTA activity. Instead of asking them for combinations of pizza toppings and bases, she asked 
her learners to choose combinations of snacks and drinks $(\mathrm{T}=$ Teacher, and $\mathrm{S}=$ Learner $)$ :

T: I think you have been very good so far so what I am going to do is invite all of you to my house. Would you be able to come?

S: Yes

T: Ja [meaning yes], but now I am only going to serve 2 types of cool drinks right because I don't have a lot of money. I could only serve coke to you or fanta. Is that okay? Now listen carefully you can't have both, you can either choose coke or you can choose fanta.

I am also going to give you some eats. I am going to give you some eats. It is going to be limited, very limited. So these are the things that I am offering to you.

So you got a variety there. Can you see? I have got almond biscuits, ginger biscuits and peppermint biscuits. You know what is that? I have some date rolls, I don't know if you like that. Date rolls, it's biscuits but it got dates in it. How many of you like that?

S: (inaudible)

T: And I have made a fruit cake as well. Okay you can see we got to do a lot of eating on Diwali Day. There's Coke and Fanta and 5 kinds of things that you can eat......

While talking to the class, Vanitha put up this list on the board with the drinks on one side and the biscuits on another side:

\begin{tabular}{|l|ll|}
\hline Coke & Almond biscuits & A \\
Fanta & Ginger biscuits & G \\
& Peppermint biscuits & P \\
& Date rolls & D \\
& Fruit cake & F \\
\hline
\end{tabular}

She continued:

T: But you can only choose 3. You can eat only 3. Okay so what are the combinations, the choice you can choose? First you got to decide whether you got to have Coke or Fanta. Now if you decide to have Coke, you can have 3 types of biscuits. Whatever it is. Okay now lets look at all the combinations. If you have Fanta you can also have 3 types of eats that's there. Any 3 combinations. All right now look at this.[points to her list] You have gotten 5 different kinds of things here. How many combinations can you have? ... What are the possible combinations that you can have? What are the possible combinations that you can have? Let's use some abbreviations here. [As Vanitha called out the abbreviations she wrote these letters next to the item it represented] Almond biscuits, what you call it? A, and ginger biscuits G, and peppermint biscuits what will we call it?

S: P

She then led her learners to list the possible combinations in the next 20 minutes. Thereafter Vanitha linked the ways in which they generated the list to the pizza problem:

T: So you know how to work with these combinations. In your activity you will read it, it has nothing to do with these combinations, it has to do with pizza ... you will have to list your combinations in this manner and the question is you have to find out how many combinations can you have?

After handing out the tasks to the learner she continued in a similar vein:

T: Ok let's look at activity 2 now. You are at a restaurant and you are looking at a pizza, you are going to buy different pizzas. Right you can either have pizza's with a thick base or you could order a pizza with a regular base. And how many toppings are there?

S: 4

The learners then completed the task during the lesson, while Vanitha walked around and emphasised the connections between the two tasks.

Later on, in an informal conversation conducted after the lesson, Vanitha explained that she had suspected that many of her learners had not experienced eating pizza and she had therefore asked the class the 
previous day, how many learners had eaten pizza before. There were six learners who had indicated that they knew what pizza was and Vanitha feared that the terms base, toppings, mushroom, salami and tuna, would be a barrier that would disconnect them from engaging with the mathematics of the task which involved carrying out the relatively simple mathematical procedure of listing the various combinations. This reasoning led her to design a similar task which was set within a context that was familiar to all her learners.

This lesson foregrounds the question: What happens when a context is out of the learners' experiences? In this situation Vanitha intervened by working through a similar question set within a known context. In order for the learners to complete the task Vanitha needed to help them understand the concept of combinations. By using a familiar context (of cool drinks and snacks), Vanitha wanted to help her learners to understand the procedures involved in generating a list of all possible combinations of elements from two given sets. The learners were then able to apply the procedure they used in the party context to the pizza context because they understood that they needed to choose between the bases firstly and then a second choice between the various toppings. At this stage they needed to just distinguish between the sets from which they could make the choices from. Once they understood the role played by the toppings and bases in the procedure, they were no longer intimidated by the unfamiliar words mushroom, salami and tuna - because they knew that the terms were part of the set from which the second choice of four elements had to be chosen. However Vanitha's intervention simplified the CTA task by reducing it to an application of a familiar operation to be performed on two sets. The consequences of the context being out of learners' experiences is explored further in another paper by the author (Bansilal, 2008), where issues around the fairness and validity of the CTA are interrogated, by using learners' responses to the pizza activity discussed in this vignette.

\section{Vignette 2: Sipho and the weather in Durban}

The following activity was under discussion in Thami's class, in a school in a township in the Durban South region. The school is a high achieving school and boasts an excellent pass rate in the matriculation examination. In the CTA lessons Thami usually went over as many as three or even four CTA activities in one lesson, leaving the learners to complete the activities in their study time. These study times were periods in the morning before school officially started or in the afternoons after the school day had ended during which the learners worked unsupervised in their classes. In this lesson Thami's discussion is centred around the activity (below) that requires learners to interpret two graphs on temperature and rainfall and thereby decide which times would be suitable for repairs.

\section{Task 1, Activity 4 (Pairs)}

Work $4 U$ intends to do the repairs in the dry season when day temperatures are as high as possible.

On the next page you will find two graphs with information about the temperatures and rainfall on Robben Island.

Use these graphs to help Work4U decide during which months they can do the work. Give reasons for your choice.

T: Now let's compare these 2 graphs. Now you notice here all right according now to the 2 graphs, you notice that on graph number one, what type of graph is that one you see there you have the horizontal axes? Horizontal axes is what you have. Horizontal axes is what you have. On your first graph what you have?

S: Months.

T: Months okay. This is January, February up to December then thereafter you see on that one you have on axes. What type of axes is that one? That is?

S: Inaudible

T: Okay thereafter if you are looking at the first graph you see, how many months?

S: Twelve. 
T: Twelve months. Okay so when I look at the graph now you find that when the months where the temperature is high so among those twelve months, when will be the temperatures be high?

S: January, February, December

T: Yes, those three thereafter you have such now according to our explanation here, they said that this company wants to do the repairs when the temperature is high. So the temperatures are high on those months that you said. So that is how you answer that one. So those months that you have said, looking at your graph. Okay thereafter they also want to do, they say repairs when the city is dry. Okay when is the city dry? Tell me when is it dry? When there is too much rainfall or when there is no rainfall? Where there is no rainfall. When do you think the city is dry?

Sipho: July.

When Thami posed a question about when the city is dry, Sipho's answer of July was related to the weather patterns in Durban. Durban usually has wet summers (in December) and dry winters (in July). The rainfall pattern represented in the graph given, was different - in the graph the rainfall in the month of July is third highest. The graph represents the rainfall pattern of Robben Island, which is in Cape Town, which was out of most of the learners' experiences. Cape Town has dry summers and wet winters which is reflected in the graph. In this instance Thami identified that the learners' everyday knowledge contradicted the context that was used in the CTA problem. So in order to clarify this issue Thami asked them to disregard the Durban experience and drew their attention to the graphs:

T: that's according to our city here in Durban, So now in your class refer to graph number 2 there. Okay in your graph 2 there is the highest rainfall in which month? Where is the highest rainfall?

Sipho: June

It is important to note that when Thami directed Sipho (and others) to look at the graph, Sipho's response that June had the highest rainfall was correct. Thami acknowledged that it was correct and then told the learners precisely how they needed to use the information from the graphs.

$\mathrm{T}$ : Okay but now they are saying here this company here, this Work4U wants to do repairs when the season is dry. So you are saying is the season is dry when there is no rainfall. Okay so you look at that [graph] and now decide amongst those tropical months you see there. You see on this month which has a small rainfall. Okay so you combine now, combine because I actually detailed for you there. They only said that this company does repair in a dry season and when the temperatures are high. Then you combine now the answer you got in number one with the one you have from number 2 [referring to the graphs in the task]. Okay so you decide which month, it means that month you see, the one that overlaps combine both number 1 and number 2.

After allowing the learners some time to consider the problem, Thami then moved on to a further activity based on the same two graphs that is given below:

\section{Task 1, Activity 5 (Individuallv)}

Macy works for Work $4 U$ and knows that her brother Camille, who is in Grade 9, is very interested in the analysis of statistical data. She prepared the following questions for him based on the information in the graphs on the next page. Please help Camille to answer the following questions.

5.1

5.2

5.3

5.4 During which months do you think the weather is more favourable for tourism?

Give reasons for your answer.

An excerpt from Thami's discussion is given below:

T: Now in 5.4 during which month do you think the weather is more favourable to tourist. When do we have a lot of tourists visiting this part and all the surrounding area?

$\mathrm{S}$ : In summer.

T: In summer. Okay, but now in your case you need to look at why is it in summer. See if you can tell me. Can you support your statement? Why in summer? 
Sipho: Because it is the holidays.

T: Its the holidays right. It's the festive season. So in our case we refer to our graph. Okay we know visitors come when it is summer. We have quite a number of people coming along to the beach. Right okay so in your case there you cannot have the tourist in the winter especially in Robben Island. You can't say you have tourist in winter when it is ice, you can't, so decide on your own why you are saying that.

Unfortunately the teacher closed the discussion at this point on this issue and asked the learners to continue with the task, without probing the learner further to see whether he understood the issue or not. This excerpt again shows Sipho's tendency to answer questions based on his everyday knowledge and experiences of the times that tourists visited Durban. When Thami asked the class why tourists visited Durban in summer, Siphos' response was because it was holidays, and not the expected answer which should have been because the weather was warmer and dryer. Durban has mild weather throughout the year. So in Sipho's experience the weather was not a determining factor in the times tourist chose to visit. More tourists visited Durban during the summer because it was holidays, probably because it is the longest holidays in the year. Other possible reasons for the higher number of visitors could be because of the longer days or because it coincided with the festive season. For the case of Cape Town the weather in winter is a deterrent to tourists, because of the low temperatures and high rainfall. Learners were expected to infer this from the graphs showing the low temperatures and high rainfall in July. Many of these learners had not been to Cape Town or other cold places and did not have the experience of the icy and wet winter described by the graphs. In Durban weather is hardly ever a deterrent - it is very common to have beach festivals during the winter holidays, because the weather in July (average $25^{\circ} \mathrm{C}$ ) is not a deterrent to tourists. In any case, Durban has high rainfall in summer and that is still not a deterrent.

Thami tried to direct their attention to the extremities of the Cape Town weather by saying: "...you cannot have the tourist in the winter especially in Robben Island. You can't say you have tourist in winter when it is ice..." In this instance Thami had identified that his learners' everyday experience was not helpful in answering the question in the CTA problem. He pointed out that the learners needed to infer their answers from the graph of temperatures in Cape Town and not from their everyday experience of tourism patterns in Durban.

It turns out that Sipho was very positive about the CTA because he saw it as offering opportunities for participation. During an interview with a group of learners from the class, Sipho commented: "I think the CTA's are, they created them to make us pass, they are good .... A lot of people are participating now, they are succeeding". Sipho's responses indicate that he felt that their participation levels were higher in the CTA, than in the usual assessments. It is important to note that the interview was conducted after the learners completed the CTA tasks, but before they received their results. These learners did not see their tasks after submitting them - they just received their scores. Had Sipho received feedback on his responses to the CTA tasks, he would not have been so positive.

Sipho's responses in the lesson described above, illustrates a difficulty associated with test items drawn from real life contexts - learners can get confused about which knowledge they should use. Cooper and Dunne (1998) point out the likelihood for confusion around what relevant knowledge should be brought to bear when answering test items set within "real life" contexts. They showed that there was a group of children in their study who had the mathematical competence but did not always demonstrate it without being induced to by the interviewer. This was because many children initially gave responses which they saw as appropriate for the setting, but was not appropriate or comprehensive enough in the context of the mathematics test. However on being probed during their interviews they were able to produce the response considered mathematically appropriate for the setting. In fact Sipho was able to interpret the information from the graph correctly, when probed by Thami, but his initial response was to relate the situation to his Durban experience.

Sipho, in one lesson, twice based his initial response on his everyday experiences and not on the graphs provided. Furthermore, Sipho's comment that they are succeeding, implies that he considered that the learners' various responses were acceptable for the CTA tasks. This reasoning was perhaps because the questions in the tasks convey the impression that different responses would be considered, unlike the usual mathematics assessment task, which usually needed a fixed procedure with a fixed final result. 
However, the reality is that even with these "real life" tasks, not all responses are considered as legitimate to the task designers. As seen in the two excerpts of classroom interaction, had Sipho responded based on his everyday experiences, his response would have been considered incorrect. Cooper and Harries (2003) has shown that many children import a variety of extra-school realistic considerations into their solutions even though the test designers intend them not to do so. Faced with some realistically contextualised items children may introduce more than they are required or expected to do. In this episode we see that the only realistic consideration that was allowed was the assumption that tourists would prefer visiting places in warm and dry weather (which is questionable anyway, since there are many who may prefer colder weather for reasons of their own). The consideration that tourist visit in summer because it was the festive holidays, was one that was not recognised by the task designers. Yet this was a reason that Sipho had offered, based on his own experiences in Durban. However his consideration that there was a link between holidays and tourists was one which was not appropriate for the task, because the legitimate answers had be drawn from an interpretation of the two graphs. Sipho's comments during the interview also demonstrate that he felt that these extra- school realistic considerations were acceptable resulting in his (erroneous) perception of having performed favourably in the CTA task.

\section{Discussion}

The move by South African education authorities to the use of contextualised assessment activities, presents many unintended consequences, some of which pose a threat to the validity and reliability of the CTA programme. The first vignette was intended to draw our attention to the possibility that for some learners the context used is out of their experience. In the vignette provided, the teacher was able to address this problem by first introducing the mathematics by using a more familiar context. Thereafter the learners applied the procedure to the unfamiliar context, with the teacher helping them to link the elements of the procedure to the previous task. This intervention by the teacher effectively simplified the task and reduced it to a rote application of a known procedure to a simplified context. This has implications for the validity of the CTA task as a summative assessment tool.

What about those learners for whom the context was out of their experience but whose teachers did not intervene to help them understand the mathematical elements or the context? There is also the possibility that the context was out of their experience of some teachers? Both the teachers and the learners would have been disadvantaged, and the fairness of the CTA as an assessment tool is implicated. (See Bansilal (2008) for some descriptions of responses from learners who did not understand what a pizza was). When a mathematics task utilises a context that is out of the learners' experience, the learner has nothing to draw upon from her/his background to understand the questions. Consequently the context itself will block the learners from understanding what is required from them. So an appropriate question to pose would be: whose "real life" contexts are being privileged in these assessment tasks which draw on these "real life" contexts?

It is important to recognise that my comments are based on the use of the contexts in externally mandated national assessment tasks, and not a typical classroom episode, where new contexts can be used to extend learners' understanding of the world around them. In a normal classroom setting their inexperience of the middle class lifestyle may not pose a barrier to their progress in understanding because of the opportunities that are available for discussion and clarification, provided of course that the teacher understands the context.

The second vignette was intended to draw our attention to the fact that certain learners tend to rely on their everyday experience when answering tasks set within real life contexts. Could there be certain learners who are more likely than others to be disadvantaged by their tendency to respond based on their experiences? Cooper and Dunne's (1998) study concerning the differences between the approach favoured by working and service class children has reference here. These authors show that working class children seem to be more predisposed than service class children to initially employ their everyday knowledge in answering mathematics test items and that this can lead to the under-estimation of their actual capacities with respect to the demands of the mathematics school curriculum. In fact an analysis of the responses to one test item showed that working class children were almost twice as likely as service class children to refer only to their everyday knowledge in answering the researcher's query. This finding 
is of concern because this study has revealed that some learners have a predisposition to employ their everyday knowledge, and their mathematical competence may not be revealed in such a situation. Learners may not provide the expected answer because they were confused about what was being asked for and not because they did not know the correct answer. In addition, within a national assessment task, they may not be given the opportunity to explain their responses.

Boaler's work (2003) concerning the SAT-9 assessment in the USA has reference here. She described the work done in a project school, Railside High, which was situated in a low income area where students had access to few financial resources both in school and at home. It was found that the Railside learners did much worse on the SAT-9 test items than in the district tests. She argues that the SAT-9 questions used long sentences and words unknown to many students new to the country (such as spool, cable crew, wired). Furthermore, she claims that the SAT-9 question assessed many things - confidence in the face of unfamiliar answers, context knowledge, and language - but none of these were indicators of mathematics knowledge.

Boaler states that there was a high correlation between socioeconomic status and SAT -9 success and that that the evidence collected from students at Railside suggests that the low performance of students in the SAT-9 is related less to mathematical understanding than it is to language, context interpretation (which relies heavily on language) and test-taking skills. She states: "Using such tests ... as a supposed tool to increase the performance of underachieving students, particularly those from low-income and ethnic minority homes does not therefore seem to be a wise decision on the part of Californian policy makers" (2003, p. 6).

Boaler's comments should influence us to pause here in South Africa and interrogate the preferred style of the CTA which is supposed to be designed in ways that promote inclusion, accommodate diversity, identify and address barriers to learning thus helping learners to succeed. However these two vignettes demonstrate that the opposite may in fact be true. The contexts used are sometimes out of the learners experiences. In this scenario, teachers would need to intervene to help learners access the context. However the teachers' interventions must be pedagogically sound without lowering the demand of the tasks. If teachers do not intervene in meaningful ways, the learners will be disadvantaged. The second vignette illustrates that certain learners tend to rely on their everyday experience by relating the task to extra-mathematical considerations which are not considered as legitimate by the task designers. Learners who have a tendency to rely on their everyday knowledge when answering these "real life" tasks are disadvantaged. The work done by Cooper and his colleagues in the UK shows that service class learners seem to be more predisposed than middle class learners to rely on their everyday experiences and are therefore more likely to be disadvantaged by these task.

So contrary to the declarations of the intentions of fairness and the stipulation that learners should not be disadvantaged by the design of the tasks, many learners may be disadvantaged, albeit unintentionally.

\section{Concluding remarks}

It is commendable that the DOE in trying to find fairer systems of assessment has made a shift towards using alternate kinds of assessment strategies. However it is crucial that these large scale assessment programmes be researched and trialed with groups of learners from diverse backgrounds to find out whether the strategies are an improvement on the pencil and paper tasks or indeed, whether they are more disadvantageous to certain learners (as suggested by the work of Cooper in the UK and Boaler in the US). It is also necessary for research to be undertaken to find out more about what support learners need in order to ensure their success and in the same vein, what type of support teachers need in order to help their learners succeed. It does not make any sense to move to alternate ways of assessment which by their very nature, demand more support in order to be successful, without a commitment to changing the levels of support available to teachers.

I end this paper by calling for more research around several issues which have been identified in this paper. Firstly, there is a need to find out whether the assessment tasks set within an extended context can be successful at assessing students' mathematical knowledge and skills at the Grade 9 level. A second question directed more generally at the use of contextualised items is: What support must be provided to 
teachers to help them understand their role in the assessment process? And a compelling fourth question in the light of South Africa's rapidly changing class system is: Which learners are more disadvantaged than others by the use of these "real life" contexts in externally mandated assessment tasks?

\section{References}

Arcavi A. (2002). The everyday and the academic in mathematics. In M. E. Brenner \& J. N. Moschovich (Eds.), Everyday and academic mathematics in the classroom (pp. 12-29). Reston, VA: The National Council of Teachers of Mathematics.

Bansilal, S. (2006). South African Grade 9 mathematics teachers, professional expertise: A situative perspective. (Unpublished doctoral dissertation). Curtin University of Technology, Perth, Australia.

Bansilal, S. (2008). Assessing the validity of the Grade 9 mathematics CTA. Paper presented at the $5^{\text {th }}$ Conference of the Association of Commonwealth Examinations and Accreditation Bodies. Umalusi, Pretoria.

Boaler, J. (1993). The role of contexts in the mathematics classroom: Do they make mathematics more real? For the learning of Mathematics, 13(2) 12-17.

Boaler, J. (2003). When learning no longer matters - standardized testing and the creation of inequality. Phi Delta Kappan, 84 (7), 502-506.

Cohen, L., Manion, L., \& Morrison, K. (2000). Research methods in education. London: Routledge Falmer.

Cooper, B, \& Harries, T. (2003). Children's use of realistic considerations in problem solving: Some English evidence. Journal of Mathematical Behavior, 22, 451-465.

Cooper, B. (1998). Assessing national curriculum mathematics in England: Exploring children's interpretations of Key Stage 2 tests in clinical interviews. Educational Studies in Mathematics, 35(1),19-49.

Cooper, B., \& Dunne, M. (1998). Anyone for tennis? Social class differences in children's responses to national curriculum mathematics testing. The Sociological Review, 46(1), 115-148.

Cooper, B., Dunne, M., \& Rodgers, N. (1997). Social class, gender, item type and performance in national tests of primary school mathematics: Some research evidence from England. Paper presented at the annual meeting of the American Educational Research Association, Chicago.

Department of Education (2002): A draft framework for the development of common tasks for assessment (CTA). Pretoria: National Department of Education.

Evans, J. T. (1995). Adults and numeracy. (Unpublished doctoral dissertation). University of London, London.

Freudenthal, H. (1983). Didactical phenomenology of mathematical structures. Dordrecht: Reidel.

Gravemeijer, K. P. E. (1994). Developing realistic mathematics education. Utrecht: Freudenthal Institute.

Linchevski, L., \& Williams, J. S. (1996). Situated intuition, concrete manipulations and mathematical concepts: The case of integers, In L. Puig \& A. Gutierrez (Eds.), Proceedings of the Twentieth Conference of the International Group for the Psychology of Mathematics Education (Vol. 3, pp. 265-272). Valencia: University of Valencia.

Moschkovich, J. N. (2002). Bringing together workplace and academic mathematical practices during classroom assessments. In M. E. Brenner \& J. N. Moschovich (Eds.), Everyday and academic mathematics in the classroom (pp. 93-110). Reston, VA: The National Council of teachers of Mathematics:

Polkinghorne, D. E. (1995). Narrative configuration in qualitative analysis. In J. A. Hatch \& R. Wisniewski (Eds.), Life History as Narrative (pp. 5-23). London: Falmer Press.

William, D. (1997). Relevance as Macguffin in mathematics education. Paper presented at the British Educational Research Association Conference, York. 